\title{
APLICABILIDADE DA COMPETÊNCIA INFORMACIONAL E DA ORGANIZAÇÃO DO CONHECIMENTO NO PROCESSO DE GESTÃO DA INFORMAÇÃO
}

\author{
INFORMATION LITERACY AND KNOWLEDGE ORGANIZATION IN INFORMATION \\ MANAGEMENT PROCESS
}

APLICABILIDAD DE LA COMPETENCIA INFORMACIONAL Y DE LA ORGANIZACIÓN DEL CONOCIMIENTO EN EL PROCESO DE GESTIÓN DE LA INFORMACIÓN

'Selma Leticia Capinzaiki Ottonicar, ${ }^{1}$ Beatriz Rosa Pinheiro dos Santos, ${ }^{1}$ Isabela Santana de Moraes

${ }^{1}$ Universidade Estadual Paulista

\section{Correspondência}

${ }^{1}$ Selma Leticia Capinzaiki Ottonicar

Universidade Estadual Paulista

Marília, SP.

Email: selma.leticia@hotmail.com

ORCID: http://orcid.org/0000-0001-6330-3904

Submetido em: 06-06-2017

Aceito em: 03-07-2017

Publicado: 24-07-2017

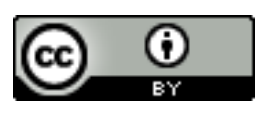

JITA: FJ. Knowledge management 
RESUMO: No atual contexto de produção e acesso da informação, as organizações precisam saber tratar as informações obtidas, seja por meio digital ou analógico. Para tanto, existe um processo conhecido como gestão da informação, responsável pela coleta, processamento, armazenagem e disseminação. Defende-se que as etapas desta gestão podem ser norteadas pela competência informacional e pela organização do conhecimento. Portanto apresentam-se os seguintes questionamentos: qual a importância da competência informacional e da organização do conhecimento na gestão da informação? Como as técnicas de organização do conhecimento e a competência informacional contribuem para a gestão da informação? O objetivo é refletir sobre a importância da competência informacional e da gestão do conhecimento para o desenvolvimento da gestão da informação inteligente, que atenda às necessidades das organizações contemporâneas. Este trabalho se justifica por inter-relacionar os temas organização do conhecimento, gestão da informação e competência informacional e sua contribuição para as organizações, caracterizando-se como tema interdisciplinar. As discussões apresentam a inter-relação entre organização do conhecimento, competência informacional e organização do conhecimento, a fim de melhorar os processos organizacionais. Como considerações finais, defende-se que os três temas propostos contribuem com a aplicação e melhoria da gestão da informação, para que os indivíduos construam conhecimento.

PAlaVRaS Chave: Gestão da Informação. Competência informacional. Gestão do conhecimento. Organização e representação do conhecimento.

ABSTRACT: In the current context of information production and access, organizations need to be able to handle the information they obtain, whether digital or analog. Therefore, there is a process known as information management, responsible for the collection, processing, storage and dissemination. It is argued that the steps of this management can be guided by informational competence and the organization of knowledge. Therefore, the following questions are raised: what is the importance of information competence and knowledge organization in information management? How do knowledge organization techniques and information competence contribute to information management? The objective is to reflect on the importance of informational competence and knowledge management for the development of intelligent information management, which meets the needs of contemporary organizations. This work is justified by interrelating the topics knowledge organization, information management and informational competence and its contribution to organizations, characterizing itself as an interdisciplinary theme. The discussions present the interrelationship between knowledge organization, informational competence and knowledge organization, in order to improve organizational processes. As final considerations, it is argued that the three proposed themes contribute to the application and improvement of information management, so that individuals construct knowledge.

KEYWORDS: Information management. Literacy information. Knowledge management. Organization and representation of knowledge.

RESUMEN: En el actual contexto de producción y acceso de la información, las organizaciones necesitan saber tratar las informaciones obtenidas, ya sea por medio digital o analógico. Para ello, existe un proceso conocido como gestión de la información, responsable de la recolección, procesamiento, almacenamiento y diseminación. Se defiende que las etapas de esta gestión pueden ser guiadas por la competencia informacional y por la organización del conocimiento. Por lo tanto, se presentan los siguientes cuestionamientos: ¿cuál es la importancia de la competencia informacional y de la organización del conocimiento en la gestión de la información? Como las técnicas de organización del conocimiento y la competencia informacional contribuyen a la gestión de la información? El objetivo es reflexionar sobre la importancia de la competencia informacional y de la gestión del conocimiento para el desarrollo de la gestión de la información inteligente, que atienda a las necesidades de las organizaciones contemporáneas. Este trabajo se justifica por interrelacionar los temas organización del conocimiento, gestión de la información y competencia informacional y su contribución a las organizaciones, caracterizándose como tema interdisciplinario. Las discusiones presentan la interrelación entre organización del conocimiento, competencia informacional y organización del conocimiento, a fin de mejorar los procesos organizacionales. Como consideraciones finales, se defiende que los tres temas propuestos contribuyen con la aplicación y mejora de la gestión de la información, para que los individuos construyan conocimiento.

Palabras Clave: Gestión de la Información. Competencia informacional. Gestión del conocimiento. Organización y representación del conocimiento.

\begin{tabular}{l|l|} 
v.15 & n.3 \\
\hline
\end{tabular}

AOP

set./dez. 2017 


\section{INTRODUÇÃ̃o}

As organizações contemporâneas necessitam de informação e conhecimento para a tomada de decisão e solução de problemas. A tecnologia da informação e comunicação tem acelerado a produção de informação tanto no contexto externo quanto interno à organização. Diariamente, os colaboradores produzem informação ao realizar suas atividades nas organizações, por isto os gestores perceberam a necessidade de gerenciá-las a fim de facilitar seu acesso, organização e tratamento.

Para estabelecer um programa de gestão da informação, é relevante considerar o impacto da competência informacional como elemento presente tanto no gestor quanto nos colaboradores. De nada adianta realizar a gestão da informação se os indivíduos têm dificuldades para acessar, avaliar e filtrar as informações disponíveis. Além disso, a competência informacional possui padrões que norteiam sua aplicação, assim acredita-se que tais elementos podem contribuir com o desenvolvimento da gestão da informação.

A internet é uma das maiores fontes de pesquisa das organizações, principalmente pela velocidade e pelo baixo custo de acesso. Por causa disso, surgem diferentes maneiras de organizar a informação que podem ser direcionadas pela organização da informação e do conhecimento. A classificação da informação e do conhecimento é utilizada pelas áreas da biblioteconomia e arquivologia, entretanto pode ser apropriada pela Gestão a fim de contribuir com o tratamento das informações e do conhecimento no contexto organizacional.

A partir das contextualizações elucidadas, apresentam-se os seguintes problemas de pesquisa: qual a importância da competência informacional e da organização do conhecimento para a gestão da informação? Como as técnicas de organização do conhecimento e a competência informacional contribuem com a gestão da informação? Esse trabalho justifica-se por inter-relacionar os temas organização do conhecimento, gestão da informação e competência informacional por meio da construção de um quadro teórico explicativo. Além disso, faz uma reflexão a respeito do desenvolvimento da gestão da informação eficaz nas organizações contemporâneas, tendo em vista a necessidade de planejar o acesso e o uso da informação.

O objetivo é refletir sobre a importância da competência informacional e da organização do conhecimento para o desenvolvimento da gestão da informação eficaz, capaz de atender às necessidades das organizações contemporâneas. Não obstante, tem como objetivo apresentar inter-relação entre organização do conhecimento, competência informacional e gestão da informação, a fim de melhorar os processos informacionais. 


\section{ORGANIZAÇÃO E REPRESENTAÇÃ̃ dO CONHECIMENTO}

A expansão da informação ocorreu junto à Revolução Industrial entre os séculos XVIII e XIX. Assim, entende-se necessidade de se estudar os processos da informação. De acordo com Pinheiro (2002), os primeiros sinais da Ciência da Informação como Campo Científico ocorreram a partir da década de 1940.

A ciência da informação é a área de estudos voltada às atividades de organização, representação e recuperação da informação. Dentre seus objetivos, possui a compreensão sobre como representar o conhecimento, quais conhecimentos podem ser representados e como cada área do saber é representada. Contudo, conhecimento e informação são termos de difícil conceituação devido à amplitude semântica e às diversas perspectivas de análise, domínios e concepções de cada área (SCHIESSL; SHINTAKU, 2012).

Para a informação ser transformada em conhecimento, o indivíduo dialoga com a sua cultura, valores, princípios, contexto, sua personalidade e sua maneira de compreender o mundo. Assim, considera-se o conhecimento como subjetivo e inerente ao sujeito, mas ao mesmo tempo social, porque as pessoas disseminam informação e conhecimento por meio da convivência (SCHIESSL; SHINTAKU, 2012).

O conhecimento está relacionado com os aspectos cognitivos que ocorrem na mente humana e os processos mentais de captação, assimilação, associação, construção, desconstrução e reconstrução de conceitos. Há, ainda, a importância do papel social do conhecimento, pois se acumula ao longo do tempo por meio da socialização (SCHIESSL; SHINTAKU, 2012).

No âmbito da ciência da informação, o conhecimento tem significação no processo individual e social, pois ele é desenvolvido, documentado e socializado em uma área, uma ciência ou em um domínio da atividade humana (CAPURRO, 2003). A organização e representação do conhecimento precisa compreender a área do documento, a fim de classificar o domínio e campo do saber, e consequentemente, representá-lo da melhor maneira possível.

A organização e representação do conhecimento faz-se necessária desde que surgiram as primeiras bibliotecas e, com o passar do tempo, suas técnicas e procedimentos foram se aprimorando para atender às necessidades de cada época.

A representação está ligada ao conceito de substituição, em que se cria uma relação entre signo e significado que também envolve considerar os símbolos. A escrita, por exemplo, é uma representação registrada em suportes, como: madeira, pedra, papel, computador, entre outros. Esses registros promoveram a evolução na produção e disseminação do conhecimento e com isso, não depende do tempo e do espaço para ser

n.3

AOP set./dez. 2017 
compartilhado. Logo, o conhecimento registrado em um livro pode ser consultado mil anos após a publicação e em diferentes locais ao redor do mundo. Representar também é um ato de conhecimento, a fim de se fazer entender (SCHIESSL; SHINTAKU, 2012).

A representação do conhecimento registrado está relacionada com as formas de simbolizá-lo. Esse processo de "simbolização" significa moldar os elementos informacionais, a fim de representá-lo e disponibilizá-lo para a disseminação e compartilhamento de informação por meio da socialização dos indivíduos.

O processo de representação pode ser entendido como uma substituição de uma entidade linguística longa e complexa por uma descrição abreviada. Esse processo envolve a análise de assunto do documento e a transformação dessa análise numa expressão linguística. Por exemplo: quando se cataloga um documento, identificam-se o autor, o título, selecionamse palavras-chave e, por fim, faz-se uma síntese para representação da informação contida no documento.

Para Brascher e Carlan (2010, p. 150), "a organização do conhecimento é um processo de modelagem que visa construir representações do conhecimento". Logo, ela é entendida como um processo de análise, síntese, classificação, organização e acesso ao objeto. Desta forma, representação e organização estão relacionadas com o objeto e com os símbolos que o substituem. Complementando, Lara e Tálamo (2007) explicam que a representação e a organização da informação são interdependentes e se utilizam das linguagens documentárias, resumos, índices, para representação, organização e posterior recuperação dos documentos e de suas informações.

A organização do conhecimento faz parte da interdisciplinaridade da Ciência da Informação, pois se relaciona com a ciência da computação, linguística, psicologia, gestão, filosofia, sociologia, entre outras. Cada qual se ocupa dos diferentes aspectos da organização do conhecimento, estes estudos englobam desde a cognição humana até os modelos de representação construídos artificialmente, como aqueles usados em sistemas computacionais (PINHEIRO, 2002).

Na perspectiva da ciência da informação, os processos de organização e representação são válidos apenas para o conhecimento socializado, ou seja, aquele que é gerado, registrado (ou não) e compartilhado para possível desenvolvimento de novos conhecimentos. Organização do Conhecimento é a construção de sistemas conceituais, e é a ciência que estrutura e organiza as compreensões inerentes ao conhecimento de modo ordenado pelos assuntos.

A organização do conhecimento é um campo que sistematiza o conhecimento para sua recuperação, um campo que tenta desempenhar um papel de comunicação e intercâmbio do conhecimento. Tem por objetivo apoiar os processos de ensino-aprendizagem, incentivar e

\begin{tabular}{l|l|} 
v. 15 & $\mathrm{n} .3$
\end{tabular}

AOP
set./dez. 2017 
oferecer subsídios às atividades de investigação científica. Esta última função é considerada como um dos pilares mais destacados no que se refere à base do campo. A organização do conhecimento existe para alcançar algum objetivo, sendo necessário desenvolver a representação para posterior organização, de acordo com as metas e valores dos usuários (HJORLAND, 2008).

Hjorland (2003) demonstra a evolução da organização a partir de cinco tecnologias estruturantes, a saber:

1- Classificação, que começou por volta de 1876 com Charles Cutter e Dewey, posteriormente Henry Bliss e Ranganathan;

2- Documentação, marco histórico em 1892 com Paul Otlet;

3- Armazenamento e recuperação, quando a ciência da informação teve grande influência dos computadores, por volta de 1950;

4- Bibliometria, que marca a possibilidade de recuperar trabalhos a partir de suas citações, ingressada em 1963 por Eugene Garfield;

5- Recuperação de texto completo e hipertexto com a internet, que marcam o atual momento e desenvolvimento da organização do conhecimento.

Destaca-se que o primeiro item, a classificação, é um sistema de organização do conhecimento. Por isso, defende-se que a organização do conhecimento se originou e se desenvolveu a partir dos princípios de seus sistemas, que são válidos, relevantes e utilizados ainda hoje, juntamente com a web semântica.

Souza, Tudhope e Almeida (2012) também afirmam que os sistemas de organização do conhecimento não são novos para a biblioteconomia, foram usados ao longo dos séculos para catálogos, como os sistemas de classificação bibliográfica e as linguagens documentárias. No entanto, atualmente está voltada à web semântica por meio da necessidade de eliminar ambiguidade e vocabulários com estruturas altamente formalizados. O objetivo da web semântica é permitir que a máquina compreenda os termos. Assim, os sistemas de organização do conhecimento variam em formato e exibição, mas compartilham a característica geral de representar conhecimento, visando promover sua recuperação.

Hjorland (2003) divide a organização do conhecimento em dois tipos: a) a organização intelectual do conhecimento, também denominada organização cognitiva, em que se utilizam conceitos, sistemas conceituais e teorias para serem organizados; b) a organização social do conhecimento, que é basicamente a organização em disciplinas, profissões, negócios e grupos sociais.

O crescimento de informações na web gerou a necessidade de novas formas de utilização de ferramentas, como tesauros, classificações e ontologias. Assim, os profissionais entendem que a construção e a implementação de sistemas organização do conhecimento são

\begin{tabular}{l|l|l} 
v.15 & n. 3 \\
\hline
\end{tabular}

AOP
set./dez. 2017 
urgentes. Tais sistemas são redes de conceitos representativos de conhecimentos para qualquer área, às vezes visto sob uma concepção filosófica ou epistemológica (BARITÉ, 2011; GARCÍA JIMÉNEZ, 2004).

O contexto atual de avanço tecnológico e o acesso ampliado à informação favorecem e estimulam a produção de conhecimento registrado. Por isso é necessária a organização de maneira rápida e eficiente, a fim de facilitar a recuperação e incentivar o acesso e, posteriormente, o desenvolvimento de novos conhecimentos. Por consequência, é essencial uma eficaz mediação no processo de organização e representação do conhecimento registrado.

O principal objetivo da organização da informação é recuperar objetos informacionais, que são as informações registradas nos mais variados suportes textos, imagens, registros sonoros, representações cartográficas e páginas web, entre outros. (SCHIESSL; SHINTAKU, 2012, p. 35)

A organização do conhecimento é entendida como a disposição dos assuntos, de maneira sistematizada e ordenada. Na ciência da informação, a organização do conhecimento é a área de estudos voltada às atividades de organização, representação e recuperação do conhecimento registrado (SCHIESSL; SHINTAKU, 2012). Para realizar as atividades de organização, representação e recuperação de documentos é fundamental que a pessoa seja competente informacional, ou seja, saiba como acessar, avaliar e usar a informação para construir conhecimento ao longo da vida.

\section{COMPETÊNCIA INFORMACIONAL}

O termo competência informacional foi oficialmente criado em 1974, nos Estados Unidos, por Paul Zurkowski no National Forum of Information Literacy. Zurkowski defendia a necessidade de um movimento teórico rumo a essa competência devido às necessidades organizacionais e sociais (DUDZIAK, 2003).

A partir de 1974, vários pesquisadores e profissionais da informação se conscientizaram sobre sua importância, e então se iniciaram os estudos da área no âmbito da ciência da informação. Cada país adaptou uma tradução do termo advindo do inglês, Information Literacy, segundo seu idioma e compreensão de seus conceitos. No Brasil, houve várias traduções do termo, tendo em vista a apropriação dos termos em inglês e espanhol. Portanto, outras terminologias também podem se relacionar com o fenômeno como competência informacional, competência em informação, letramento informacional, alfabetização informacional, entre outros.

Sabe-se que a variação de uso dos termos do estado da arte, no Brasil, tem incitado discussões calorosas por parte dos pesquisadores da área, entretanto, conforme explica Ottonicar (2016), os conceitos e contribuições do fenômeno são mais importantes que sua discussão terminológica. Portanto, adotou-se o tempo "competência informacional" nesse 
artigo por ser sugerido como mais adequado pela revista.

A Competência informacional é vista como uma competência funcional da sociedade moderna, pois contribui para que o indivíduo exerça sua cidadania e seja integrado socialmente (BELLUZZO; FERES, 2015). Assim, tal competência contribui para que o cidadão saiba acessar a fonte informação em diferentes suportes, como o analógico e digital; saiba como avaliar a informação e suas fontes por meio da identificação da desinformação e das intenções e ideologias que acompanham o texto; e saiba usar a informação em sua vida pessoal, profissional e social, a fim de tomar uma decisão e compreender o mundo de maneira crítica.

Essa competência é formada por duas dimensões diferentes, mas complementares: a primeira dimensão envolve o conjunto de capacidades e habilidades que possibilitam a aplicação prática dos conhecimentos na sociedade; e a segunda envolve o pensamento crítico em relação ao contexto social em que vive o indivíduo (BELLUZZO, 2007). Complementando Belluzzo (2007), a Association of College and Research Libraries (ACRL) acrescenta:

\begin{abstract}
As definições anteriores de competência informacional a descrevem como sendo um conjunto de habilidades ou competências que são uniformes para todos os aprendizes... Outras concepções, crescendo a partir das concepções de Bruce, Lupton, Lloyd e Limburg, identificam as limitações desta concepção baseada apenas nas habilidades e atributos individuais. O compartilhamento das descobertas destes autores enfatizam a natureza contextual e altamente relacional da competência informacional e as circunstâncias várias nas quais os indivíduos e grupos ativam estas competências e as descrevem para os pesquisadores. Claramente, a experiência de estudar, trabalhar e viver em um ambiente informacional complexo produz uma variedade de modelos de competência informacional potenciais através de uma variedade de disciplinas, domínios, contextos e ambientes de trabalho. (ACRL, 2014, p.4, tradução nossa)
\end{abstract}

Essa nova conceituação da ACRL (2014) demonstra que os conceitos de competência informacional tiveram uma nova evolução em relação a sua compreensão ao considerar os fatores comportamentais, cognitivos e as experiências dos indivíduos como culminantes ao desenvolvimento dessa competência. Essa nova compreensão iniciou-se a partir da década de 2000 por meio da disseminação da pesquisa fenomenográfica de Bruce (2000), e, a partir de então, há um movimento forte, no continente Europeu e Oceania, voltado a estas novas abordagens.

No contexto da sociedade da informação, os profissionais necessitam conhecer as necessidades dos usuários a fim de contribuir com a construção e conhecimento. Para melhor disponibilizar os recursos nas unidades de informação, é fundamental organizar os objetos, livros, vídeos, revistas, entre outros. Assim, o profissional realiza a organização do conhecimento registrado de diversas maneiras a fim de que o usuário possa recuperá-lo de maneira eficaz. Para organizar o conhecimento de maneira inteligente, o indivíduo necessita saber como acessar, avaliar e usar a informação de maneira inteligente, ações incluídas na

\begin{tabular}{l|l|l}
$\mathrm{v} .15$ & $\mathrm{n} .3$ \\
\hline
\end{tabular}

AOP
set./dez. 2017 
compreensão de competência informacional.

Para realizar a gestão da informação, é necessário saber como acessar, avaliar as fontes e usar a informação para atingir um objeto, solucionar um problema ou tomar uma decisão. Além disso, não se pode esquecer o papel da organização do conhecimento nesse processo considerado como elemento base para a gestão da informação nas unidades de informação e demais organizações.

\section{GESTÃO DA INFORMAÇÃO}

O termo Gestão da Informação pode ser encontrado nos trabalhos de Paul Otlet, principalmente em seu livro, do ano de 1934, intitulado Traité de documentation, que foi grande referência no desenvolvimento da gestão da informação da época, conhecida como documentação. Atualmente, grande parte do conhecimento envolvido e advindo da gestão da informação possui suas origens nos trabalhos de Paul Otlet. O conceito de gerência de recursos informacionais foi originalmente sugerido por Robert S. Taylor, na década de 1960. Também é importante salientar que, além de Paul Otlet, mais dois autores se revelaram pioneiros da gestão da informação atual: Frederick Hayek e Vanevar Bush (BARBOSA, 2008).

Nesse contexto, torna-se relevante destacar que a gestão da informação possui como característica a interdisciplinaridade em sua aplicação, pois, de acordo com Barbosa (2008), se fundamenta em três campos importantes: a administração (Gestão), a Ciência da Computação e a Ciência da Informação.

A Gestão da Informação (GI) auxilia as organizações a lidarem com uma variedade de insumos informacionais, a fim de utilizá-los na tomada de decisão, na produção de novos conhecimentos e na competitividade das organizações (CARVALHO, 2012). No entanto, para Silva e Tomaél (2007), a GI não se encarrega apenas de gerenciar os insumos informacionais internos de uma organização, pois também se responsabiliza por gerenciar as informações externas de uma empresa. Esta gestão é uma disciplina que contempla todos os fluxos e ações referentes à informação, ao invés de considerar apenas os sistemas de informação. Além disso, os autores afirmam que a GI está relacionada com o conhecimento coletado, processado e gerenciado, desta forma também está amparada nos conteúdos da gestão do conhecimento.

De acordo com Oliveira (2010), em busca de atingir eficientemente os objetivos de uma organização, a GI está dividida em três níveis hierárquicos: operacional, estratégico e tático. O nível mais baixo da pirâmide exige mais especificidade na resolução dos problemas, enquanto o nível mais alto está focado nas decisões estratégicas de modo mais amplo. Reginato e Gracioli (2012) consideram que administrá-la de forma inteligente e fazendo seu uso como um recurso estratégico pode contribuir diretamente e de maneira efetiva, para o

\begin{tabular}{|c|c|c|c|c|c|}
\hline (C) RDBCI: Rev. Digit. Bibliotecon. Cienc. Inf. & Campinas, SP & v. 15 & n.3 & AOP & set./dez. 2017 \\
\hline
\end{tabular}


planejamento organizacional.

A GI pode ser considerada um processo constituído pela identificação das necessidades de informação, coleta, tratamento, apresentação da informação, classificação e armazenamento, elaboração de um produto e/ou serviço, disseminação, e disponibilização da informação para análise e uso (McGEE e PRUSAK, 1994). Choo (1998) corrobora a definição de McGee e Prusak (1994), afirmando que a gestão da informação pode ser denominada como um ciclo e um processo de atividades informacionais que estão relacionadas. Além disso, defende que a GI se integra com a gestão da tecnologia da informação e com a gestão dos recursos informacionais.

De acordo com Ponjuán Dante (2007), a GI pode ser considerada um processo de implantação e utilização de recursos básicos presentes em uma organização (financeiros, físicos, humanos, materiais) com o objetivo de gerenciar a informação interna e externa.

Assim, com base nessas explanações acerca da GI, pode-se afirmar que, as organizações contemporâneas necessitam da organização do conhecimento da gestão da informação, a fim de contribuir com as atividades de rotina dos profissionais. Entretanto, precisam ser competentes em informação para lidar com as informações todos os dias. Ponjuán Dante (2007) complementa essa afirmação, pois a autora explica que a GI possibilita que os indivíduos compreendam diferentes aspectos. Por exemplo, vários tipos de informação, o fluxo de informação, o ciclo de vida da informação e o conhecimento profissional.

A GI de uma organização exige que os indivíduos tenham o domínio dos diferentes tipos de informação que perpassam uma empresa, da dinâmica dos fluxos nos diferentes processos nos quais está presente a informação, do ciclo de vida de cada informação e do conhecimento dos profissionais sobre a GI (PONJUÁN DANTE, 2007).

A autora ainda expressa que uma gestão da informação eficaz

exige não apenas conhecer as fontes, serviços e sistemas, seu ciclo de vida e seus critérios de qualidade, mas também ter bem definidas as políticas relacionadas ao papel da gestão da informação. Assim, as pessoas podem ser, em um plano dinâmico do fluxo de informação, geradores, receptores ou vigilantes do armazenamento da informação. (PONJUÁN DANTE, p.30, 2007)

Nessa conjuntura, pode-se afirmar que o contexto da GI é interdisciplinar, pois envolve outras disciplinas que podem ser acolhidas em seu processo, no intuito de melhorar seu serviço. Nesse caso, relaciona-se à organização do conhecimento, cujo papel dentro da GI é organizar, representar e recuperar a informação e o conhecimento. Não obstante, possui diálogo com a competência informacional que objetiva tornar competente um indivíduo para o acesso, avaliação das fontes e uso a informação de forma inteligente e efetiva. Defende-se 
que essa inter-relação traz benefícios para a GI e para o contexto das organizações contemporâneas.

\section{DISCUSSÃ̃o}

$\mathrm{Na}$ literatura, existem diferentes modelos para exemplificar e demonstrar as etapas da gestão da informação nas organizações. Dentre eles, escolheu-se o modelo de Choo (2003), que apresenta seis etapas do processo: identificação das necessidades informacionais, aquisição da informação, organização e armazenamento da informação, desenvolvimento de produtos e serviços de informação, distribuição da informação e, por fim, uso da informação.

Cada etapa necessita ser realizada de maneira eficaz e, para tanto, a organização deve contar com um profissional competente em informação. Esta competência norteia as habilidades e capacidades dos indivíduos por meio de padrões e indicadores estabelecidos internacionalmente. No Brasil, Belluzzo (2007) traduziu e adaptou os padrões de acordo com o contexto brasileiro e, portanto, a perspectiva dessa autora foi adotada para o desenvolvimento do Quadro 1.

As etapas de organização do conhecimento podem ser realizadas com o auxílio de diferentes sistemas de organização do conhecimento. Desta forma, serão propostas etapas de maneira genérica com base nas semelhanças gerais dos sistemas mais utilizados a partir da literatura da área.

É necessário analisar a organização do conhecimento socializado e compreender a função de mediação das ferramentas que oferecem suporte à Organização do Conhecimento. Estas ferramentas são conhecidas como sistemas de organização do conhecimento, como, por exemplo, tesauro, taxonomia, sistemas de classificação, ontologias. Assim, a organização do conhecimento responsabiliza-se pela construção de ferramentas para a recuperação do conhecimento registrado, portanto o objeto de estudo é o documento (HJORLAND, 2003; 2008).

Barité (2001) relaciona dez premissas básicas, oferecendo justificativa intelectual para a organização do conhecimento:

1- O conhecimento é um produto social, uma necessidade social e um dínamo social;

2- O conhecimento é realizado a partir da informação, e ao socializar pode ser transformado novamente em informação;

3- A estrutura e comunicação do conhecimento formam um sistema aberto;

4- O conhecimento deve ser organizado para seu melhor aproveitamento individual e social;

5- Existem muitas formas possíveis de organizar o conhecimento;

6- Toda organização do conhecimento é artificial; 
7- O conhecimento se registra sempre em documentos, como conjunto organizado de dados disponíveis, admite usos indiscriminados;

8- O conhecimento se expressa em conceitos e se organiza mediante sistemas de conceitos;

9- Os sistemas de conceitos se organizam para fins científicos, funcionais ou de documentação;

10- As leis que regem a organização de sistemas de conceitos são uniformes e previsíveis e se aplicam por igual a qualquer área disciplinar.

Entre as premissas de Barité (2001), acrescenta-se a relevância e necessidade da organização do conhecimento, já que o conhecimento deve ser organizado para seu melhor aproveitamento. Não obstante, existem diferentes formas de organizá-lo como um conjunto de dados disponíveis que admite usos diversos. O conhecimento se organiza mediante sistemas de conceitos, além disso, toda organização do conhecimento é artificial, sendo esta uma abstração e representação da realidade. Desta forma, entende-se que a organização do conhecimento é responsável pela sistematização ordenada do conhecimento e o modo como os assuntos são disponibilizados cujo principal objetivo é a socialização e a criação de novos conhecimentos.

Com base nas premissas de Barité (2001) e nas afirmações de Hjorland (2003; 2008), propõem-se seis etapas genéricas para o processo de organização do conhecimento registrado. Essas etapas estão inter-relacionadas com as etapas de gestão da informação de Choo (2003) e os padrões e indicadores de competência informacional proposto por Belluzzo (2007).

Quadro 1. A relação entre gestão da informação, competência informacional e organização do conhecimento.

\begin{tabular}{|c|c|c|}
\hline $\begin{array}{l}\text { Etapas da Gestão da } \\
\text { Informação }\end{array}$ & $\begin{array}{c}\text { Padrões e indicadores de Competência em } \\
\text { Informação }\end{array}$ & $\begin{array}{l}\text { Etapas do processo de } \\
\text { Organização do } \\
\text { conhecimento }\end{array}$ \\
\hline $\begin{array}{l}\text { Identificação das } \\
\text { necessidades } \\
\text { informacionais }\end{array}$ & $\begin{array}{l}\text { Padrão } 1 \text { - A pessoa competente em } \\
\text { informação determina a natureza e a extensão da } \\
\text { necessidade de informação. }\end{array}$ & $\begin{array}{l}\text { Reconhecimento do } \\
\text { material. }\end{array}$ \\
\hline $\begin{array}{l}\text { Aquisição da } \\
\text { Informação }\end{array}$ & $\begin{array}{c}\text { Padrão } 2 \text { - A pessoa competente em } \\
\text { informação acessa a informação necessária com } \\
\text { efetividade. }\end{array}$ & $\begin{array}{l}\text { Classificação do } \\
\text { documento. }\end{array}$ \\
\hline $\begin{array}{l}\text { Organização e } \\
\text { armazenamento da } \\
\text { informação }\end{array}$ & $\begin{array}{c}\text { Padrão } 3 \text { - A pessoa competente em } \\
\text { informação avalia criticamente a informação e } \\
\text { as suas fontes. }\end{array}$ & Tratamento do conteúdo. \\
\hline $\begin{array}{l}\text { Desenvolvimento de } \\
\text { produtos e serviços de } \\
\text { informação }\end{array}$ & $\begin{array}{l}\text { Padrão } 4 \text { - A pessoa competente em } \\
\text { informação, individualmente ou como membro } \\
\text { de um grupo, usa a informação com efetividade } \\
\text { para alcançar um objetivo/obter um resultado. }\end{array}$ & $\begin{array}{l}\text { Representação do } \\
\text { conhecimento. }\end{array}$ \\
\hline $\begin{array}{l}\text { Distribuição da } \\
\text { informação }\end{array}$ & $\begin{array}{l}\text { Padrão } 4 \text { - A pessoa competente em } \\
\text { informação, individualmente ou como membro } \\
\text { de um grupo, usa a informação com efetividade }\end{array}$ & $\begin{array}{l}\text { Armazenamento do } \\
\text { documento. }\end{array}$ \\
\hline
\end{tabular}




\begin{tabular}{|c|c|c|}
\hline & para alcançar um objetivo/obter um resultado. & \\
\hline Uso da informação & Padrão 5 - A pessoa competente em & Apresentação do \\
& informação compreende as questões \\
& conhecimento. \\
& uso da informação e acessa e usa a informação \\
& ética e legalmente. & \\
\hline
\end{tabular}

Fonte: Elaborado pelas autoras com base em Choo (2003), Belluzzo (2007), Barité e Hjordland (2003; 2008).

A terceira coluna do Quadro 1 compreende as etapas propostas para uma adequada organização do conhecimento. A primeira é o reconhecimento do material, ou seja é o primeiro contato físico e/ou virtual digital do profissional da informação com o material que será organizado. Posteriormente, é realizada a próxima etapa de desconstrução do material, conhecida como a classificação do documento. Esta etapa envolve a identificação da tipologia do documento, como sendo um livro, jornal, quadro ou qualquer outro conteúdo informacional que será organizado.

A próxima etapa é o tratamento do conteúdo, isto é, a compreensão da natureza do conteúdo e da área do conhecimento dos conceitos ali expressos. Em sequência, é realizada a representação do conhecimento, na qual o profissional da informação representa as informações por meio da linguagem documentária e identifica a comunidade que poderá utilizá-lo. Essa representação é feita a partir de uma análise do conteúdo do documento para que o usuário consiga atingir seus objetivos de uso da informação. Já no armazenamento do documento há o depósito nas prateleiras físicas ou a inserção em um espaço digital. Essa etapa visa à harmonia dos termos de busca nas bases de dados e sua exposição nas prateleiras.

A apresentação do conhecimento é a última etapa na qual o conhecimento é disponibilizado para acesso ao usuário, de maneira eficaz. Considera-se que a informação devidamente organizada deve ser disponibilizada para acesso, a fim de que os usuários possam encontrá-la e utilizá-la facilmente. Desta forma, devem-se observar principalmente os suportes e os termos utilizados para essa representação. Percebe-se também a necessidade de que a linguagem documentária seja próxima à utilizada pela comunidade, assim é especialmente elaborada para possibilitar o pleno acesso às informações.

A primeira etapa da gestão da informação, a identificação das necessidades informacionais, mostra que o profissional deve ser capaz de perceber quais informações precisa para solucionar o problema ou tomar uma decisão (CHOO, 2003). Não obstante, é fundamental reconhecer o tipo de material ou suporte do documento, se é analógico ou digital e como poderá ser aproveitado para o acesso a informação. Nessa etapa, é fundamental que o indivíduo saiba como determinar a natureza e a extensão da necessidade de informação (BELLUZZO, 2007), com base em seus conhecimentos e experiências. Nesse sentido, a pessoa deve compreender as necessidades dos profissionais, clientes ou usuários. Essa etapa requer análise das atividades realizadas pelos indivíduos, atreladas aos objetivos organizacionais. 
O processo de aquisição da informação (CHOO, 2003) envolve o conhecimento das tecnologias da informação e comunicação (TIC) e a busca de informações na tecnologia analógica, como é o caso das fontes de informação impressas. Assim, é preciso fazer um levantamento das fontes disponíveis sobre determinado assunto em diferentes formatos, inclusive as fontes informais, como é o caso das pessoas. Essas ações fazem parte do tratamento da informação da organização do conhecimento. Portanto, a pessoa competente em informação acessa a informação necessária com efetividade, por meio da seleção dos métodos mais apropriados de busca e/ou sistemas de recuperação da informação, constrói e implementa estratégias de busca delineadas com efetividade, busca a informação via eletrônica ou com pessoas, utilizando uma variedade de métodos, retrabalha e melhora a estratégia de busca quando necessário e extrai, registra e gerencia a informação e suas fontes (BELLUZZO, 2007).

Posteriormente, há a fase de organização e armazenamento da informação (CHOO, 2003), que envolve conhecer os suportes que possibilitarão a recuperação da informação. Esta fase também envolve tratar o tipo do documento se é livro, jornal, revista ou digital, conforme expõe a organização do conhecimento. O profissional deve: avaliar criticamente a informação e suas fontes, para demonstrar conhecimento da maior parte das ideias da informação obtida; articular e aplicar critérios de avaliação para a informação e para as fontes; e comparar o novo conhecimento com o conhecimento anterior, para determinar o valor agregado, contradições ou outra característica da informação (BELLUZZO, 2007).

O desenvolvimento de produtos e serviços de informação ocorre por meio do empacotamento da informação obtida (CHOO, 2003), ou seja, o seu registro formal com base nas tabelas, gráficos ou mapas. O empacotamento é entendido como tratamento da informação pela gestão do conhecimento, pois ambos envolvem a interpretação do conteúdo. Assim, o indivíduo usa a informação para alcançar um resultado e é capaz de sintetizar a informação para desenvolver ou completar um projeto e trabalha a informação, utilizando esquemas ou estruturas diversas (BELLUZZO, 2007).

Depois de organizar e armazenar a informação, o profissional deve realizar a distribuição da informação a fim de possibilitar sua recuperação por outras pessoas, estimulando a aprendizagem (CHOO, 2003). Antes de disseminar o documento é necessário armazenar a informação, conforme detalha o processo de organização do conhecimento. $\mathrm{O}$ armazenamento é importante para que a informação seja recuperada no futuro. Desse modo, o profissional competente em informação, individualmente ou como membro de um grupo, usa a informação, comunica os resultados do projeto e conhece as normas de documentação vigentes e sabe como citar o conteúdo informacional (BELLUZZO, 2007).

Finalmente, o processo de uso da informação concretiza-se por meio da tomada de decisão organizacional (CHOO, 2003) ou solução de problemas encontrados nas organizações. A organização do conhecimento explica que para usar a informação é

\begin{tabular}{l|l|l} 
v.15 & n. 3
\end{tabular}

AOP set./dez. 2017 
fundamental que o documento seja apresentado de maneira eficaz em um dado suporte. Além disso, o uso ocorre em diferentes níveis, pois pode estar relacionado a uma decisão que mudará o futuro da organização. Ressalta-se que a tomada de decisão também faz parte das pequenas escolhas da rotina de trabalho que compõe a experiência do profissional. Nessa etapa, o profissional constrói o conhecimento ao compreender as questões econômicas, legais e sociais da ambiência do uso da informação e acessa e usa a informação ética e legalmente, conforme explicou Belluzzo (2007).

Há, portanto, a construção da aprendizagem, pois compreende as questões legais, éticas e socioeconômicas que envolvem a informação, a comunicação e a tecnologia. Além disso, cumprem-se as leis, regulamentos, políticas institucionais e normas relacionadas ao acesso e uso das fontes de informação e indicam-se as fontes de informação nas comunicações do produto ou resultados independentemente do suporte escolhido (BELLUZZO, 2007). O profissional que é responsável pela GI tem como objetivo final o uso da informação voltado a um objetivo específico, assim como a competência informacional e a organização do conhecimento.

\section{CONSIDERAÇõES FINAIS}

Neste trabalho, buscou-se verificar qual a importância da competência informacional e da organização do conhecimento na gestão da informação. Refletiu-se que o reconhecimento do material é o primeiro contato do profissional da informação com o conhecimento. Para realizar tal ação, a organização necessita de um profissional competente informacional, que consiga determinar a natureza e a extensão da sua necessidade de informação.

A inter-relação demonstrou que o profissional que avalia de forma crítica a informação, sua natureza e suas fontes se torna capaz de tratar o conteúdo de maneira eficiente, e, por consequência, a organização e o armazenamento da informação são realizados a fim de atingir o objetivo final, o uso da informação.

A representação do conhecimento, por meio do aprofundamento da análise do conteúdo do material, propicia ao profissional a utilização da informação para alcançar um objetivo com efetividade. Esse processo resulta no desenvolvimento competente de produtos e serviços de informação. Com isso, o profissional precisa conhecer o conteúdo do documento e ser capaz de interpretá-lo a parti das informações disponíveis.

A disponibilização do conhecimento é o resultado da disseminação da informação para as pessoas. Além disso, os indivíduos necessitam compreender as questões economicas, éticas, legais e sociais do uso da informação, a fim de desenvolver a representação do conhecimento. Tanto a gestão da informação, quanto a competencia informacional e a organização do conhecimento disseminam as informações a fim de que sejam utilizadas pela 
comunidade e organização.

Por fim, compreende-se que o profissional competente em informação realiza a organização do conhecimento de forma eficiente e, ainda, estimula a avaliação de todo o processo para identificar os possíveis erros, ação conhecida por feedback. Assim, a informação e o conhecimento podem ser acessados, avaliados e usados de maneira inteligente e eficaz para gerar novos conhecimentos por meio da gestão da informação que é baseada na competência informacional e na organização do conhecimento.

\section{REFERÊNCIAS}

ACRL. First part of the draft framework for information literacy for higher education. Disponível em: < http://acrl.ala.org/ilstandards/wp-content/uploads/2014/02/Framework-forIL-for-HE-Draft-1-Part-1.pdf >. Acesso em: 09 jan. 2017.

BARBOSA, Ricardo Rodrigues. Gestão da informação e do conhecimento: origens, polêmicas e perspectivas. Informação \& Informação, Londrina, v. 13, no especial, 2008. Disponível em: < http://www.uel.br/revistas/uel/index.php/informacao/article/view/1843 >. Acesso em: 19 abr. 2017.

BARITÉ, Mario. Organización del conocimiento: un nuevo marco teórico-conceptual en Bibliotecología y Documentación. In: CARRARA, Kester. (Org.). Educação, universidade e pesquisa. Marília: Unesp-Marília-Publicações, 2001. p.35-60.

Sistemas de organización del conocimiento: uma tipologia actualizada. Informação \& Informação, Londrina, v. 16, nº especial, p. 122-139, jan./jun. 2011.

BELluZZO, Regina Celia Baptista. Construção de mapas: desenvolvendo competências em informação e comunicação. Bauru: Cá Entre Nós, 2007.

.; FERES, Glória Georges. Competência em informação, redes de conhecimento e as metas educativas para 2021: reflexões e inter-relações. In: BELLUZZO, Regina Celia Baptista.; FERES, Glória Georges. Redes de conhecimento e competência em informação: interfaces da gestão, mediação e uso da informação/organização. Rio de Janeiro: Interciência, 2015, p.1-35.

BRASCHER, Marisa.; CARLAN, Eliana. Sistemas de organização do conhecimento: antigas e novas linguagens. In: ROBREDO, Jaime.; BRASCHER, Marisa. (Org.). Passeios pelos bosques da informação: estudos sobre representação e organização da informação e do conhecimento. Brasília: IBICT, 2010. p. 147-176.

BRUCE, Christine. Information literacy programs and research: reflections on 'Information literacy programs and research: An International review'. The Australian Library Journal, v.49, n.3, p.209-218, 2000. Disponível em: < http://dx.doi.org/10.1080/00049670.2011.10722653 >. Acesso em: 05 abr. 2017. 
CAPURRO, Rafael. Epistemologia e ciência da informação. Tradução: Ana Maria Rezende Cabral, Eduardo Wense Dias, Isis Paim, Ligia Maria Moreira Dumont, Marta Pinheiro Aun e Mônica Erichsen Borges. In: ENCONTRO NACIONAL DE PESQUISA EM CIÊNCIA DA INFORMAÇÃO, 5., 2003, Belo Horizonte. Anais... Belo Horizonte: Escola de Ciência da Informação, UFMG, 2003.

CARVALHO, Lívia Ferreira de. Gestão da Informação em Micro e Pequenas Empresas: um estudo do arranjo produtivo local de confecção do vestuário de Jaraguá-GO. Perspectivas em Gestão \& Conhecimento, João Pessoa, v.2, n. esp, p. 57-72, out. 2012. Disponível em: < http://periodicos.ufpb.br/index.php/pgc/article/view/12598/8018 >. Acesso em: 02 abr. 2017.

$\mathrm{CHOO}$, Chun Wei. Information management for the intelligent organization: the art of scanning the environment. 2.ed. [s.1.: ASIS], 1998.

A organização do conhecimento: como as organizações usam a informação para criar significado, construir conhecimento e tomar decisões. São Paulo: Senac, 2003.

DUDZIAK, Elisabeth Adriana. Information literacy: princípios, filosofias e práticas. Ciência da Informação, Brasília, v.32, n.1, p. 23-35, jan./abr. 2003. Disponível em: < http://revista.ibict.br/ciinf/index.php/ciinf/article/view/123/104 >. Acesso em: 12 fev. 2017.

GARCÍA JIMÉNEZ, Antonio. Instrumentos de representación del conocimiento: tesauros versus ontologias. Anales de Documentación, n.7, p. 79-95, 2004. Disponível em: < http://revistas.um.es/analesdoc/article/view/1691/1741 >. Acesso em: 12 abr. 2017.

HJORLAND, B. Fundamentals of knowledge organization. Knowledge Organization, v. 30, n. 2, p. 87-111, 2003.

B. What is knowledge organization (KO)? Knowledge Organization, v. 35, n. 2/3, p.86-101, 2008.

LARA, Marilda Lopes Ginez de.; TÁLAMO, Maria Fátima Gonçalves. Uma experiência na interface Linguística Documentária e Terminologia. DataGramaZero, v.8, n.5, out. 2007. Disponível em: < http://basessibi.c3sl.ufpr.br/brapci/index.php/article/view/0000007759/d50ccddef59b7aa3edf acdffce8228ee >. Acesso em: 02 fev. 2017.

McGEE, James.; PRUSAK, Laurence. Gerenciamento estratégico da informação: aumente a competitividade e a eficiência de sua empresa utilizando a informação como uma ferramenta estratégica. Rio de Janeiro: Campus, 1994.

OLIVEIRA, Joelma de Souza Passos de. A gestão da informação como suporte ao processo de tomada de decisão em uma instituição pública de ensino superior: um estudo de caso. 163f. 2010. Dissertação (Mestrado em Ciência, Gestão e Tecnologia da Informação) - Setor de Ciências Sociais Aplicadas, Universidade Federal do Paraná, Curitiba, 2010.

OTTONICAR, Selma Letícia Capinzaiki. Análise teórico-descritiva da competência em informação de gestores como fator de competitividade das indústrias de

n.3
AOP set./dez. 2017 
eletroeletrônicos da cidade de Garça/SP. 272f. 2016. Dissertação (Mestrado em Ciência da Informação) - Programa de Pós-Graduação em Ciência da Informação, Universidade Estadual Paulista - Faculdade de Filosofia e Ciências, Marília, 2016.

PINHEIRO, Lena Vania Ribeiro. Ciência da Informação: desdobramentos disciplinares, interdisciplinaridade e transdisciplinaridade. Rio de Janeiro: IBICT/MCT, 2002.

PONJUÁN DANTE, Gloria. Gestión de información: dimensiones e implementación para el éxito organizacional. Gijón: Trea, 2007.

REGINATO, Carlos Eduardo Roehe.; GRACIOLI, Odacir Deonísio. Gerenciamento estratégico da informação por meio da utilização da inteligência competitiva e da gestão do conhecimento - um estudo à indústria moveleira do RS. Gest. Prod, São Carlos, v.19 n.4, p. 705-716, 2012. Disponível em: < http://www.scielo.br/pdf/gp/v19n4/a04v19n4.pdf >. Acesso em: 02 abr. 2017.

SCHIESSL, Marcelo.; SHINTAKU, Milton. Sistemas de Organização do conhecimento. In: ALVARES, Lilian (Org.). Organização da informação e do conhecimento: conceitos, subsídios interdisciplinares e aplicações. São Paulo: B4 editores, 2012, p. 49-118.

SILVA, Teresinha Elisabeth da.; TOMAÉL, Maria Inês. A gestão da informação nas organizações. Informação \& Informação, v.12, n.2, jul./dez. 2007. Disponível em: < www.uel.br/revistas/uel/index.php/informacao/article/download/1806/1540 >. Acesso em: 19 abr. 2017.

SOUZA, Renato Rocha.; TUDHOPE, Douglas.; ALMEIDA, Maurício Barcellos. Towards a taxonomy of KOS: dimensions for classifying knowledge organization systems. Knowledge Organization, v. 39, n. 3, p. 179-192, 2012. Disponível em: < http://mba.eci.ufmg.br/downloads/Souza_Tudhope_Almeida_KOS_Taxonomy.Submitted.p df >. Acesso em: 17 fev. 2017.
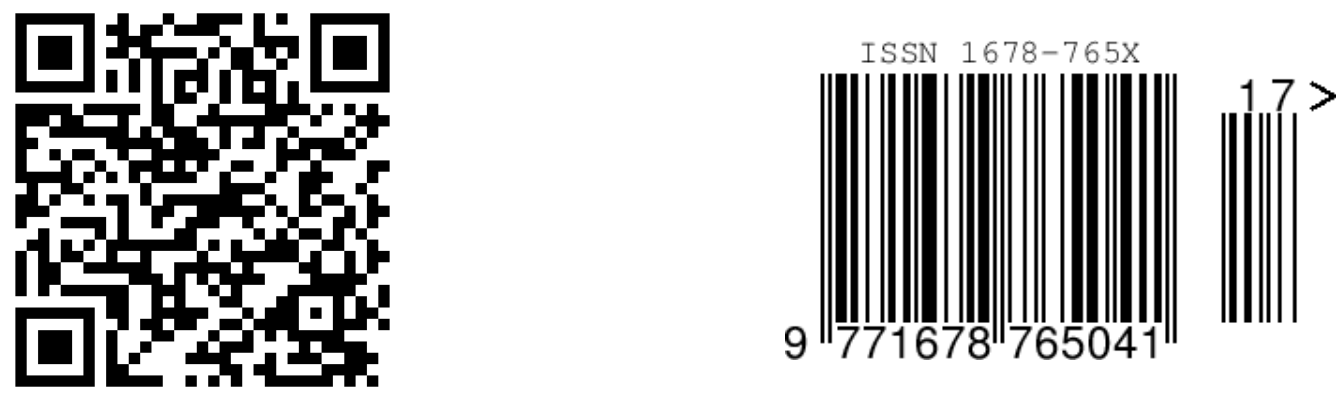